\title{
Dry matter yield of dryland and irrigated mixtures of Caucasian clover, white clover and perennial ryegrass over 5 years at Lincoln University
}

\author{
A.D. BLACK and R.J. LUCAS
}

Field Research Centre, Department of Agricultural Sciences, PO Box 85084, Lincoln University, Lincoln 7647, New Zealand alistair.black@lincoln.ac.nz

\begin{abstract}
This experiment investigated the effects of Caucasian clover (CC), white clover (WC), perennial ryegrass $(\mathrm{RG})$ and their mixtures on dry matter (DM) yield under dryland and irrigated conditions over 5 years (1st July-30th June) at Lincoln University. Seven mixtures of the three species (three pure, three binary and one ternary) were sown in November 1999, grown with and without irrigation, and grazed by sheep. Total annual DM yield in Years 2-6 (2000/2001-2004/2005) was analysed. Clover-RG mixtures yielded more than the average monoculture yields of their constituent species (over-yielding). This diversity effect was 1.8-7.0 t $\mathrm{DM} / \mathrm{ha}$ for WC-RG over all 5 years and 2.7-4.6 t DM/ ha for CC-RG in Years 3-6. There was no additional yield benefit from the three-species mixture. Diversity effects were due to synergistic interactions between the clovers and RG, which were similar for $\mathrm{CC}$ and WC once established. The interspecific interactions persisted despite changes in botanical composition across irrigation levels and years.
\end{abstract}

Keywords: competition, diversity, Lolium perenne, pasture, Trifolium ambiguum, Trifolium repens, weeds

\section{Introduction}

The advantage of Caucasian clover (Trifolium ambiguum; $\mathrm{CC}$ ) over traditional legumes has been illustrated in a number of animal and pasture production studies (Taylor \& Smith 1998). For example, at an irrigated lowland site in Canterbury, Black et al. (2007) reported greater liveweight gain for lambs grazing mixed CC-ryegrass (Lolium perenne; RG) pastures than white clover ( $T$. repens; WC)-RG pastures. Similarly, in Wisconsin, USA, Mouriño et al. (2003) showed that the liveweight gain of steers on CC-grass pastures was $20 \%$ greater than on red clover (T. pratense)-grass pastures. These greater animal liveweight gains have been attributed to the higher legume content in the $\mathrm{CC}$ pastures.

In addition, pasture-based studies have frequently reported greater yields for $\mathrm{CC}$ than other clover species in a range of temperature, soil moisture and fertility conditions (Daly \& Mason 1987; Moss et al. 1996; Taylor \& Smith 1998; Virgona \& Dear 1996; Scott 2001). For example, on light volcanic soils in coastal
Bay of Plenty, Watson et al. (1998) showed that in spring a 3-year-old CC-RG pasture had 10 to $20 \%$ higher growth rates than a WC-RG pasture. As drought intensified in mid-summer, both pastures produced less than $10 \mathrm{~kg}$ of dry matter $(\mathrm{DM}) / \mathrm{ha} / \mathrm{day}$, but the CC-RG pasture had five times the legume content of the WC$R G$ pasture. Few of these studies have investigated how these growth rate differences with $\mathrm{CC}$ affect the yield of mixed species pasture.

The yield of a pasture mixture can be directly related to the effects of species identity and diversity (Kirwan et al. 2009). The identity effect is the monoculture yield of each species. The diversity effect is the difference between the actual yield of the mixture and the yield expected from the monocultures due to multiple interspecific interactions (e.g., niche partitioning and facilitation). Interspecific interactions may differ in direction (i.e., synergistic or antagonistic) and magnitude, and can involve two or more species. The contributions of species' identities and interactions to pasture yield are weighted by the initial proportions of species in the pasture. For a study over several years, the initial species' proportions may be the composition of yield from the previous year. Widdup et al. (2001) has shown that $\mathrm{N}_{2}$ fixation rates of $\mathrm{CC}$ and $\mathrm{WC}$ are the same and directly proportional to the amount of clover DM produced. However, there is no current information on the effects of interspecific interactions between CC and other species.

This paper reports yield results from Years 2 to 6 of an experiment that compared monocultures and mixtures of $\mathrm{CC}, \mathrm{WC}$ and $\mathrm{RG}$ in dryland and irrigated conditions. Seasonal yield data from Years 2 and 3 of the clover monocultures in this experiment have been reported previously (Black et al. 2003). The objectives were to investigate the identity and diversity effects of the three species on annual DM yield and determine whether these effects persisted across dryland and irrigated conditions, and with age of the pasture.

\section{Methods}

Experimental design and site

Seven mixtures of 'Endura' CC, 'Demand' WC and 'Nui' RG (three pure, three binary and one ternary) were compared with and without irrigation in a split- 
plot design with three replicates. Irrigation was the main plot factor and mixture was the sub-plot factor. Sub-plot size was $4.2 \times 6.0 \mathrm{~m}$. The design was laid out in Iverson Field at Lincoln University, Lincoln, New Zealand (43⒊ $38^{\prime} 51.5^{\prime \prime} \mathrm{S} 172^{\circ} 27^{\prime} 59.7^{\prime \prime} \mathrm{E}$ and $9 \mathrm{~m}$ a.s.1.). The soil was a Wakanui silt loam (Cox 1978) with a water holding capacity of $310 \mathrm{~mm} / \mathrm{m}$ depth. The site had been in chickpea (Cicer arietinum) in 1998 and RG in 1999. Annual (1st July-30th June) rainfall and potential evapotranspiration were 687 and $906 \mathrm{~mm}$ for 1999/2000 (Year 1), 485 and $1048 \mathrm{~mm}$ for 2000/2001, 699 and $953 \mathrm{~mm}$ for 2001/2002, 461 and $1017 \mathrm{~mm}$ for 2002/2003, 493 and $986 \mathrm{~mm}$ for 2003/2004, 635 and $934 \mathrm{~mm}$ for 2004/2005 and 670 and $1060 \mathrm{~mm}$ for the long term mean, respectively. Average monthly air temperature ranged from $4^{\circ} \mathrm{C}$ in July to $16^{\circ} \mathrm{C}$ in January. Climate data were obtained from Broadfields Meteorological Station located $3 \mathrm{~km}$ north of the site.

\section{Mixture establishment and management}

The clover seed was lime-coated and inoculated with Rhizobium leguminosarum bv. trifolii strain ICC148 for $\mathrm{CC}$ and $\mathrm{CC} 275 \mathrm{e}$ for WC. The RG was infected with Epichloë festucae var. lolii (syn. Neotyphodium lolii) endophyte AR1. Thousand seed weight was 4.4, 1.2 and $2.4 \mathrm{~g}$, germination was 90,99 and $98 \%$, and the sowing rate in both monocultures and mixtures was 8,2 and 6 $\mathrm{kg} / \mathrm{ha}$ for CC, WC and RG, respectively.

The site was cultivated into a seedbed in OctoberNovember 1999. Sulphur superphosphate (8\% P, 19\% S) was applied at $250 \mathrm{~kg} / \mathrm{ha}$ during cultivation. The mixtures were sown on 9th November 1999 using an Øyjord precision drill with 14 coulters spaced $150 \mathrm{~mm}$ apart. Sowing depth was $10-15 \mathrm{~mm}$. By 25th January 2000 , clover establishment in the CC, WC and CCWC plots was only about 40 plants $/ \mathrm{m}^{2}$ (23\% of sown seed). Therefore, more CC (16 kg/ha) and WC (4 kg/ha) seed was hand sown into these plots on 17th February 2000 (at the first grazing) in an attempt to accelerate the establishment of complete canopies.

The plots were grazed by sheep between August and May, three times in Year $1(1999 / 2000)$, nine times in Year 2, seven times in Years 3 and 4, five times in Year 5 and eight times in Year 6. The grazing management permitted the average pre-grazing herbage mass (HM) to range from 1.5 to $3.5 \mathrm{t} \mathrm{DM} / \mathrm{ha}$ and the grazing period to range from 4 to 11 days. Sufficient sheep were used to remove most of the herbage and the residual was trimmed to $3-4 \mathrm{~cm}$.

The insecticide Chlor-P 480EC $(240 \mathrm{~g} / \mathrm{ha}$ chlorpyrifos) was sprayed for greasy cutworm (Agrotis ipsilon) on 24th November 1999. Weed control involved one spray of 2,4-DB $(2.4 \mathrm{~kg} / \mathrm{ha} 2,4-\mathrm{DB})$ for broadleaf weeds on 23rd December 1999 and regular hand weeding of mainly wireweed (Polygonum aviculare) in
Year 1. Gallant (250 g/ha haloxyfop) was sprayed on the CC, WC and CC-WC plots to control grass weeds (mainly Poa annua and Critesion spp.) in September 2000, September 2001 and November 2003.

Soil fertility (May 2001) was: $\mathrm{pH}$ 6.2, Olsen P 25 $\mathrm{mg} / \mathrm{L}, \mathrm{Ca} 8.2 \mathrm{me} / 100 \mathrm{~g}, \mathrm{Mg} 1.1 \mathrm{me} / 100 \mathrm{~g}, \mathrm{~K} 1.1 \mathrm{me} / 100$ $\mathrm{g}$, Na $0.24 \mathrm{me} / 100 \mathrm{~g}$ and sulphate $\mathrm{S} 8 \mathrm{mg} / \mathrm{kg}$.

During Year 1, all plots were irrigated to prevent a soil water deficit of $25 \mathrm{~mm}$ to $0.5 \mathrm{~m}$ depth to assist pasture establishment. For subsequent years, the irrigated treatment received water every 3-5 weeks, post-grazing, between November and April using a mobile trickle tape irrigation system. The system applied water at $8-10 \mathrm{~mm} / \mathrm{h}$ and aimed to prevent a soil water deficit of more than $100 \mathrm{~mm}$ to $1.5 \mathrm{~m}$ depth based on a soil water budget:

$\mathrm{A}=\sum \mathrm{PET}-(\mathrm{R}+\mathrm{I})$ (Equation 1)

where the amount of water required $(\mathrm{A})$ is equal to the difference between potential evapotranspiration (PET) and rainfall (R) plus irrigation (I) in the previous period.

In Year 3, irrigated treatments also received $48 \mathrm{~mm}$ and dryland treatments $166 \mathrm{~mm}$ of water on 22nd August-20th September 2001, because rainfall had not recharged soil water completely during the previous winter (Black et al. 2003). The amount of water applied to the irrigated treatment/annum was $510,300,450$, 450 and $300 \mathrm{~mm}$ for Years 2 to 6 , respectively.

\section{Measurements}

Before each grazing, herbage in one $0.2 \mathrm{~m}^{2}$ quadrat/plot was clipped to $1-2 \mathrm{~cm}$ above ground, bagged and stored at $3-4^{\circ} \mathrm{C}$. Within 1-4 days of collection, a subsample was separated into each sown species and total weed species. Volunteer (not sown) WC and RG could not be separated from sown plants of the same species and so did not form part of the weed fraction. However, volunteer plants of WC and RG that were not sown in a plot were included in weed. The separated components and the rest of the sample were dried at $65^{\circ} \mathrm{C}$ and weighed to determine herbage mass (HM). Because the post-grazing residual was trimmed to $3-4 \mathrm{~cm}$, and the quadrats were cut to $1-2$ $\mathrm{cm}$, the residual HM had to be estimated. To do this, one $0.20 \mathrm{~m}^{2}$ quadrat per monoculture and ternary plot was clipped to $1-2 \mathrm{~cm}$ above ground and dried at $65^{\circ} \mathrm{C}$. The residual HM of the binary and ternary plots was then calculated as the average monoculture residual/replicate, weighted by species' proportions in the previous pregrazing HM. Calculated and measured values for the ternary plots were not significantly different. Pre-grazing HM minus the previous residual HM was the DM yield. This was multiplied by the proportions of species and weed in the subsample to determine their DM yields. The yields were summed across harvests within each year (June-July).

\section{Data analysis}


Total yield (annual DM yield) was analysed for Years 2 to 6 . Analysis of variance (ANOVA) tested effects of mixture and irrigation for each year using Genstat ${ }^{\circledR} 18$. Means were compared using Fisher's least significant difference test $(\alpha=0.05)$. Over-yielding (mixtures yielding greater than the average monoculture yields of the constituent species, weighted by the initial species' proportions) was tested using paired samples t-tests. This additional yield is the diversity effect. Mixture and irrigation effects on the diversity effect were also tested by ANOVA. A repeated measures analysis tested whether the identity and diversity effects persisted over the 5 years.

Total yield was also analysed relative to the proportions of sown species in the mixtures by fitting a quadratic model to the data for each year in Minitab ${ }^{\circledR}$ 18. The model was:

$\hat{y}=\beta_{1} x_{1}+\beta_{2} x_{2}+\beta_{3} x_{3}+\beta_{12} x_{1} x_{2}+\beta_{13} x_{1} x_{3}+\beta_{23} x_{2} x_{3}+$ $\beta_{123} x_{1} x_{2} x_{3}+\beta_{1} x_{1} I+\beta_{2} x_{2} I+\beta_{3} x_{3} I+\beta_{12} x_{1} x_{2} I+\beta_{13} x_{1} x_{3} I$ $+\beta_{23} x_{2} x_{3} I+\beta_{123} x_{1} x_{2} x_{3} I+\varepsilon$ (Equation 2).

$\hat{y}$ is the predicted total yield of a mixture. The variables $\mathrm{x}_{1}, \mathrm{x}_{2}$ and $\mathrm{x}_{3}$ are the initial proportions of $\mathrm{CC}, \mathrm{WC}$ and $R G$, respectively, in the sown yield (annual DM yield of sown species) from the previous year. $\beta_{1}, \beta_{2}$ and $\beta_{3}$ are estimates of the monoculture total yields (identity effects). The species proportions in the sown yield from Year 1 averaged 5:95, 5:95, 20:80 and 2:20:78 for CCWC, CC-RG, WC-RG and CC-WC-RG, respectively. $\beta_{12}, \beta_{13}$ and $\beta_{23}$ represent the interaction effects for the combination of two species and $\beta_{123}$ is the additional interaction between three species. Species identity and interaction effects are weighted by the initial species' proportions. The diversity effect of a mixture is the sum of all the species interaction terms. Terms with ' $I$ ' test the effect of irrigation on species identities and interactions ('I' was coded -1 for dryland and 1 for irrigated). $\varepsilon$ is the residual. The ANOVA for the mixture model tested if the estimated regression coefficients were significantly different $(\mathrm{P}<0.05)$ from zero or not. There were no t-tests and $\mathrm{P}$ values for the first three coefficients because the model does not have an intercept term.

\section{Results and Discussion}

The total yield, sown species yields and weed yield are shown for each monoculture and mixture in dryland and irrigated conditions for each year (Figure 1). Total yield was affected by mixture and irrigation and these effects depended on year $(\mathrm{P}<0.001)$. However, mixture effects on total yield did not depend on irrigation. Therefore, the species identity and diversity effects on total yield persisted across the dryland and irrigated conditions, but changed over the 5 years.

Monoculture total yield was greatest for WC and lowest for CC in Year $2(2000 / 2001)$, but it was greatest for $\mathrm{CC}$ in Years 3, 4 and 6 for both dryland and irrigated systems (Figure 1). Several mixtures exceeded $(\mathrm{P}<0.05)$ the monoculture total yields and there was over-yielding. The CC-RG mixture exceeded the average monoculture total yield of its constituent species at each irrigation level in Years 3-6, whereas the WC-RG and CC-WC-RG mixtures exceeded the average monoculture total yields of their constituent species in all 5 years. The diversity effect (additional yield) of the over-yielding mixtures was greater $(\mathrm{P}<0.05)$ for irrigated than dryland swards in Year 2, greater $(\mathrm{P}<0.05)$ for $\mathrm{WC}-\mathrm{RG}$ and $\mathrm{CC}-\mathrm{WC}-\mathrm{RG}$ than CC-RG mixtures in Year 3, and consistent across mixtures, irrigation levels and over time in Years 4-6 (Table 1). These results show the species identity and diversity effects responded to the slower establishment of CC (Black et al. 2006a, b) and its subsequent yield advantage (Black et al. 2003) compared to WC and RG, which persisted from Year 3 to 6 .

Table 1 Diversity effects for total dry matter yield ( $\mathrm{t} / \mathrm{ha}$ ) in response to mixture and irrigation for each year.

\begin{tabular}{|c|c|c|c|c|c|c|c|c|c|c|}
\hline \multirow[t]{3}{*}{ Mixture } & \multicolumn{10}{|c|}{ Year by irrigation } \\
\hline & \multicolumn{2}{|c|}{$2000 / 2001$} & \multicolumn{2}{|c|}{$2001 / 2002$} & \multicolumn{2}{|c|}{$2002 / 2003$} & \multicolumn{2}{|c|}{$2003 / 2004$} & \multicolumn{2}{|c|}{$2004 / 2005$} \\
\hline & D & I & D & I & D & I & D & I & D & I \\
\hline CC-RG & - & - & 4.6 & 3.5 & 4.2 & 3.2 & 2.7 & 3.3 & 3.4 & 4.3 \\
\hline WC-RG & 3.0 & 7.0 & 6.4 & 6.2 & 2.1 & 3.7 & 1.8 & 3.9 & 2.0 & 2.3 \\
\hline CC-RG-WC & 2.9 & 6.2 & 6.5 & 4.6 & 3.3 & 3.6 & 3.1 & 2.1 & 3.5 & 2.3 \\
\hline SED & \multicolumn{2}{|c|}{1.68} & \multicolumn{2}{|c|}{1.07} & \multicolumn{2}{|c|}{1.43} & \multicolumn{2}{|c|}{1.49} & \multicolumn{2}{|c|}{1.01} \\
\hline Mixture & \multicolumn{2}{|c|}{ NS } & \multicolumn{2}{|c|}{ * } & \multicolumn{2}{|c|}{ NS } & \multicolumn{2}{|c|}{ NS } & \multicolumn{2}{|c|}{ NS } \\
\hline Irrigation & \multicolumn{2}{|c|}{ * } & \multicolumn{2}{|c|}{ NS } & \multicolumn{2}{|c|}{ NS } & \multicolumn{2}{|c|}{ NS } & \multicolumn{2}{|c|}{ NS } \\
\hline Interaction & \multicolumn{2}{|c|}{ NS } & \multicolumn{2}{|c|}{ NS } & \multicolumn{2}{|c|}{ NS } & \multicolumn{2}{|c|}{ NS } & \multicolumn{2}{|c|}{ NS } \\
\hline
\end{tabular}

2000/2001 was Year 2 of the swards. CC $=$ Caucasian clover, $W C=$ white clover, RG = perennial ryegrass, D = dryland, I = irrigated, SED = standard error of difference between means, NS = not significant, ${ }^{*}=\mathrm{P}<0.05$. 

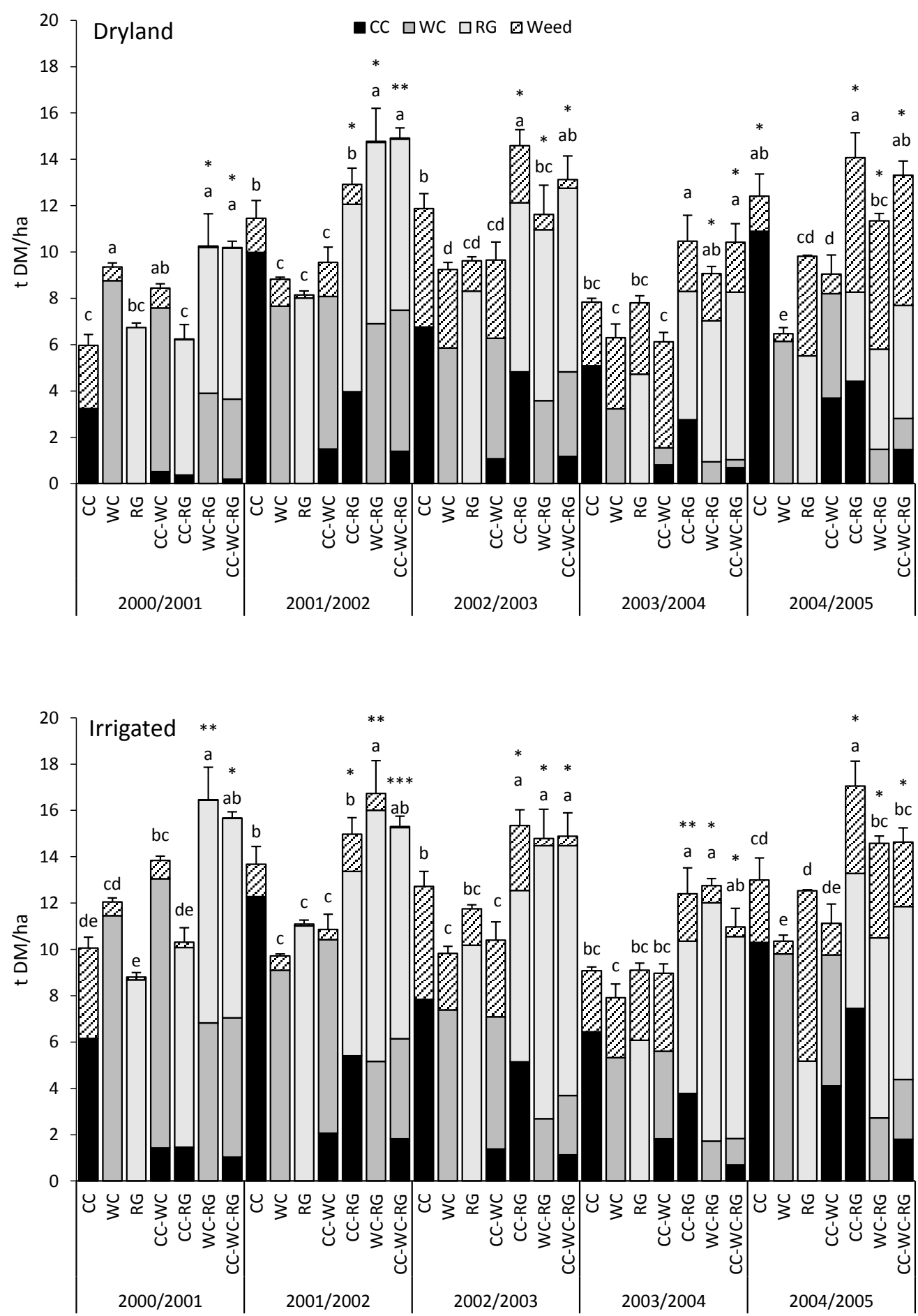

Figure 1 Total, sown species and weed dry matter (DM) yields for monocultures and mixtures of Caucasian clover (CC), white clover (WC) and perennial ryegrass (RG) for each year in dryland and irrigated conditions at Lincoln University. Error bars are standard errors of means for total yield. Total yields within year and irrigation level with different letters are significantly different $(P<0.05)$. Asterisks indicate significance of test for over-yielding * $^{*}$ $\mathrm{P}<0.05,{ }^{* *} \mathrm{P}<0.01,{ }^{\star * \star} \mathrm{P}<0.00$ 
The yields of sown species and weeds showed great variation across monocultures and mixtures, irrigation levels and years (Figure 1). For example, the yield of $\mathrm{CC}$ in the dryland CC-RG mixture, expressed as the proportion of sown yield, increased from 0.06 in Year 2 to 0.33 in Year 3 and 0.52 in Year 6. By comparison, the yield of WC in the dryland WC-RG mixture was 0.38 of sown yield in Year 2, 0.48 in Year 3 and 0.27 in Year 6 . Similar results were obtained for irrigated mixtures. Weed ingress was evident in all swards. Therefore, total yield reflected the ability of the swards to convert available resources into DM of the sown species as well as the weed species. This showed that the overyielding generally persisted alongside major changes in botanical composition across irrigation levels and years.

The estimated coefficients from the mixture regression model quantified the separate interspecific interactions that led to the diversity effects and overyielding (Table 2). The coefficients for the linear terms (e.g., CC) represent the monoculture total yields (identity effects) and were equal to the monoculture yields already shown (Figure 1). The coefficients for the quadratic terms (e.g., CC*WC) indicated differences between the three pairwise interaction effects on total yield. There were no interactions between $\mathrm{CC}$ and $\mathrm{WC}$, and positive and significant interactions between $\mathrm{CC}$ and RG, and WC and RG. The absence of interactions between CC and WC indicates both of those species had the ability to fix atmospheric N (Widdup et al. 2001). It also suggests that differences in seedling growth (Black et al. 2006a, b), seasonal growth and rooting depth (Black et al. 2003) between the two species did not result in niche partitioning or facilitation of soil moisture or nutrients other than N. This hypothesis needs further investigation.

The coefficients of the significant pairwise interaction terms represent the potential of the species involved to interact in an even mixture (Table 2). The large positive coefficient of 31.2 for WC-RG in Year 2 indicated a strong synergy between WC and RG. The synergism of CC with RG was stronger than WC with RG in Year 3, as indicated by the larger coefficient of 43.4, and similar to WC-RG in each subsequent year. These coefficients can be used to quantify the diversity effect. In Year 3 , the average diversity effect for a 50:50 mixture of $\mathrm{CC}$ and $\mathrm{RG}$ was $10.8 \mathrm{t} \mathrm{DM} / \mathrm{ha}(43.4 \times 1 / 4)$, whereas for a 50:50 mixture of WC and RG it was $6.5 \mathrm{t} \mathrm{DM} / \mathrm{ha}$ $(26.1 \times 1 / 4)$. This suggests that $\mathrm{CC}$ had the potential to facilitate the growth of RG better than WC in an even mixture. The explanation for this result is not clear from this study, particularly because soil $\mathrm{N}$ status was not estimated. However, one reason may be RG dominance and a depletion of soil $\mathrm{N}$ for the CC-RG mixture across the first 3 years of the swards. Furthermore, there was no evidence that the two clovers had the potential to interact differently with RG in subsequent years. Therefore, once established, both clovers appeared to

Table 2 Estimated regression coefficients from the mixture model for total dry matter yield (t/ha) for each year.

\begin{tabular}{|c|c|c|c|c|c|c|c|c|c|c|}
\hline \multirow[t]{3}{*}{ Term } & \multicolumn{10}{|c|}{ Year } \\
\hline & \multicolumn{2}{|c|}{$2000 / 2001$} & \multicolumn{2}{|c|}{$2001 / 2002$} & \multicolumn{2}{|c|}{$2002 / 2003$} & \multicolumn{2}{|c|}{$2003 / 2004$} & \multicolumn{2}{|c|}{$2004 / 2005$} \\
\hline & Coef. & SE Coef. & Coef. & SE Coef. & Coef. & SE Coef. & Coef. & SE Coef. & Coef. & SE Coef. \\
\hline $\mathrm{CC}$ & 8.01 & 0.590 & 12.6 & 0.492 & 12.3 & 0.486 & 8.46 & 0.546 & 12.7 & 0.505 \\
\hline WC & 10.7 & 0.590 & 9.27 & 0.492 & 9.54 & 0.486 & 7.10 & 0.546 & 8.41 & 0.505 \\
\hline$R G$ & 7.77 & 0.590 & 9.61 & 0.492 & 10.7 & 0.486 & 8.45 & 0.546 & 11.2 & 0.505 \\
\hline$C C^{\star} W C$ & 12.0 & 17.2 & 7.99 & 8.31 & -0.220 & 4.11 & 1.32 & 4.87 & -0.540 & 2.55 \\
\hline $\mathrm{CC}^{\star} \mathrm{RG}$ & 10.3 & 17.2 & 43.4 & 7.14 & 15.9 & 2.60 & 12.4 & 2.80 & 17.0 & 2.76 \\
\hline$W C^{\star} R G$ & 31.2 & 4.78 & 26.1 & 2.52 & 12.4 & 2.48 & 14.7 & 3.64 & 18.2 & 5.62 \\
\hline$C C^{*} W C^{\star} R G$ & -165 & 279 & -151 & 78.1 & 13.7 & 32.0 & -39.1 & 55.1 & 143 & 127 \\
\hline$C C^{\star} I$ & 2.05 & 0.590 & 1.11 & 0.492 & 0.424 & 0.486 & 0.624 & 0.546 & 0.294 & 0.505 \\
\hline$W C^{\star} I$ & 1.35 & 0.590 & 0.444 & 0.492 & 0.292 & 0.486 & 0.809 & 0.546 & 1.94 & 0.505 \\
\hline$R G^{\star} I$ & 1.04 & 0.590 & 1.47 & 0.492 & 1.07 & 0.486 & 0.649 & 0.546 & 1.36 & 0.505 \\
\hline$C C^{\star} W C^{\star} I$ & 27.7 & 17.2 & 1.87 & 8.31 & 0.380 & 4.11 & 4.41 & 4.87 & -0.850 & 2.55 \\
\hline $\mathrm{CC}^{\star} \mathrm{RG}^{\star} \mathrm{I}$ & 20.0 & 17.2 & -4.35 & 7.14 & -1.96 & 2.60 & 1.36 & 2.80 & 2.21 & 2.76 \\
\hline$W C^{\star} R G^{\star} I$ & 12.6 & 4.78 & -0.340 & 2.52 & 3.44 & 2.48 & 6.04 & 3.64 & 1.52 & 5.62 \\
\hline $\mathrm{CC}^{\star} \mathrm{WC}^{\star} \mathrm{RG}^{\star} \mathrm{I}$ & -244 & 279 & -82.7 & 78.1 & -19.8 & 32.0 & -116 & 55.1 & -190 & 127 \\
\hline
\end{tabular}

2000/2001 was Year 2 of the swards. CC = Caucasian clover, WC = white clover, RG = ryegrass, I = irrigation (coded -1 for dryland and 1 for irrigated), SE $=$ standard error. Emboldened values are significantly different from zero $(P<0.05)$. 
have a similar ability to fix atmospheric N, which can facilitate the growth of legumes and companion species in low N soils (Andrews et al. 2011). In this study, the plots were grazed in common by sheep and, because $\mathrm{N}$ fixation-facilitated growth of companion species depends largely on $\mathrm{N}$ recycling in urine, the diversity effects observed in this experiment may be modified under conditions of closed-grazing treatments.

The absence of significant interactions between all three species (i.e., the coefficients of the $\mathrm{CC}^{*} \mathrm{WC} * \mathrm{RG}$ term) showed no additional benefit to total yield from increasing the number of sown species from two to three in the mixture (Table 2). This helps to explain the similar, and sometimes lower, over-yielding for CC-WC-RG than CC-RG and WC-RG (Figure 1 and Table 1). The diversity effect for CC-WC-RG was the aggregate of all the pairwise and three-species interactions operating in that mixture, which varied in magnitude and direction (Table 2). For example, in Year 3, the average potential diversity effect for an even $(1 / 3-1 / 3-1 / 3)$ CC-WC-RG mixture was $3.0 \mathrm{t} \mathrm{DM} / \mathrm{ha}(7.99 \mathrm{x}$ $1 / 9+43.4 \times 1 / 9+26.1 \times 1 / 9-151 \times 1 / 27)$, which was less than the diversity effects calculated earlier for even CC-RG and WC-RG mixtures. These results show that the two clovers had a greater potential to interact with $\mathrm{RG}$ when they were the sole legume species rather than when they were in the same mixture.

The mixture model also revealed how irrigation affected individual species identity and interspecific interaction effects (Table 2). The coefficients of the species-by-irrigation terms (e.g., CC*I) were all positive, significantly so for all species in Year 2, CC and $R G$ in Year 3, RG in Year 4, and $\mathrm{WC}$ and $\mathrm{RG}$ in Year 6. This confirmed that monoculture total yields generally increased with irrigation. For example, in Year 2, the identity effect for CC was $6.0 \mathrm{t} \mathrm{DM} / \mathrm{ha}$ with no irrigation $(8.01-2.05)$ and $10.1 \mathrm{t} \mathrm{DM} /$ ha with irrigation $(8.01+2.05)$. The coefficients of the other irrigation terms showed that irrigation generally did not affect the CC-RG and WC-RG interactions, except in Year 2 when the diversity effect of a 50:50 WC-RG mixture was $4.7 \mathrm{t} \mathrm{DM} / \mathrm{ha}$ in dryland $(31.2 \times 1 / 4-12.6 \times$ $1 / 4)$ and $10.9 \mathrm{t} \mathrm{DM} /$ ha with irrigation $(31.23 \times 1 / 4+12.6$ $\times 1 / 4)$. Therefore, the CC-RG and WC-RG interaction effects on total yield generally persisted across the dryland and irrigated conditions.

The interspecific interactions on total yield also generally persisted despite the changes in sown species and weed compositions across irrigation levels and years (Figure 1). However, the magnitude of these interaction effects depended on the relative proportions of sown species involved. This helps to explain why there was no diversity effect for CC-RG in Year 2, and why the diversity effect was generally similar for CC-RG and $\mathrm{WC}-\mathrm{RG}$ in Years
4-6 (Table 1). The CC and RG had the ability to interact synergistically, but CC was not present in large enough abundance in Year 2 and therefore the expression of this interaction was not strong enough to detect (Kirwan et al. 2009). However, its increased abundance in each subsequent year resulted in the improved yield benefits (Figure 1).

\section{Conclusions}

The clover-RG mixtures yielded more than the average monoculture yields of their constituent species (overyielding). The diversity effect was 1.8-7.0 t DM/ha for WC-RG over all 5 years and 2.7-4.6 t DM/ha for CC-RG in Years 3-6. Diversity effects persisted across the dryland and irrigated conditions. There was no additional yield benefit from the three-species mixture over the binary CC-RG and WC-RG mixtures. The mixture model quantified the interspecific interactions that contributed to the diversity effects, in response to the species composition of sown yield from the previous year. The diversity effects were due to synergistic interactions between the clovers and RG, which were similar for $\mathrm{CC}$ and $\mathrm{WC}$ once established. The interspecific interactions persisted despite changes in botanical composition across dryland and irrigated conditions and age of pasture.

\section{ACKNOWLEDGEMENTS}

Authors acknowledge the C. Alma Baker, Struthers and Pukehou Poutu Trusts for financial assistance.

\section{REFERENCES}

Andrews, M.; James, E.K.; Sprent, J.I.; Boddey, R.M.; Gross, E.; dos Reis Jr, F.B. 2011. Nitrogen fixation in legumes and actinorhizal plants in natural ecosystems: values obtained using ${ }^{15} \mathrm{~N}$ natural abundance. Plant Ecology and Diversity 4: 131-140.

Black, A.D.; Lucas, R.J.; Moot, D.J.; Sedcole, J.R. 2007. Liveweight gains of lambs from Caucasian clover/ryegrass and white clover/ryegrass swards on soils of high and low fertility. Grass and Forage Science 62: 225-238.

Black, A.D.; Moot, D.J.; Lucas, R.J. 2003. Seasonal growth and development of Caucasian and white clovers under irrigated and dryland conditions. Legumes for dryland pastures. Grasslands Research and Practice Series 11: 81-90.

Black, A.D.; Moot, D.J.; Lucas, R.J. 2006a. Spring and autumn establishment of Caucasian and white clovers with different sowing rates of perennial ryegrass. Grass and Forage Science 61: 430-441.

Black, A.D.; Moot, D.J.; Lucas, R.J. 2006 b. Development and growth characteristics of Caucasian and white clover seedlings compared with perennial ryegrass. Grass and Forage Science 61: 442-453. 
Cox, J.E. 1978. Soils and agriculture of part Paparua County, Canterbury, New Zealand. New Zealand Soil Bureau Bulletin No. 34. New Zealand Department of Scientific and Industrial Research, Wellington, New Zealand. 128 pp.

Daly, G.T.; Mason, C.R. 1987. Performance of Caucasian and zigzag clovers. Proceedings of the New Zealand Grassland Association 48: 151-156.

Kirwan, L.; Connolly, J.; Finn, J.A.; Brophy, C.; Lüscher, A.; Nyfeler, D.; Sebastià, M.-T. 2009. Diversity-interaction modelling: estimating contributions of species identities and interactions to ecosystem function. Ecology 90: 2032-2038.

Moss, R.A.; Burton, R.N.; Allan, B.E. 1996. Productivity of Caucasian clover based pastures under irrigation. Proceedings of the New Zealand Grassland Association 58: 177-181.

Mouriño, F.; Albrecht, K.A.; Schaefer, D.M.; Berzaghi, P. 2003. Steer performance on kura clover-grass and red clover-grass mixed pastures. Agronomy Journal 95: 652-659.

Scott, D. 2001. Sustainability of New Zealand high- country pastures under contrasting development inputs. 7. Environmental gradients, plant species selection, and diversity. New Zealand Journal of Agricultural Research 44: 59-90.

Taylor, N.L.; Smith, R.R. 1998. Kura clover (Trifolium ambiguum M.B.) breeding, culture, and utilization. Advances in Agronomy 63: 153-178.

Virgona, J.M.; Dear, B.S. 1996. Comparative performance of Caucasian clover (Trifolium ambiguum cv. Monaro) after 11 years under lowinput conditions in south-eastern Australia. New Zealand Journal of Agricultural Research 39: 245253.

Watson, R.N.; Neville, F.J.; Bell, N.L. 1998. Caucasian clover performance in a year of severe drought. Proceedings of the New Zealand Grassland Association 60: 119-125.

Widdup, K.H.; Purves, R.G.; Black, A.D.; Jarvis, P.; Lucas, R.J. 2001. Nitrogen fixation by Caucasian clover and white clover in irrigated ryegrass pastures. Proceedings of the New Zealand Grassland Association 63: 171-175. 
